\title{
Structure of human voltage-dependent calcium channel (VDCC) $\beta 3$ subunit gene
}

\author{
Yoon-Jeong Chang, ${ }^{1}$ Kyung Hea Cho, ${ }^{2}$ \\ Yong-Sook Hong, ${ }^{3}$ Sang-Moo Lee $^{3}$ and \\ Hyung-Lae Kim ${ }^{3,4}$ \\ 1 Department of Anatomy, College of Medicine, Korea University, \\ Seoul 136-705, Korea \\ 2 Department of Biology, College of Natural Sciences, \\ Seoul Women's University, Seoul 139-774, Korea \\ 3 Department of Biochemistry, and Section of Molecular Biology, \\ Medical Research Center, College of Medicine, \\ Ewha Womans University, Seoul 158-056, Korea \\ 4 Corresponding author
}

Accepted 5 November 1997

Abbreviation: VDCC, voltage-dependent calcium channel

\begin{abstract}
In excitable and endocrine organs, calcium influxes through the voltage-dependent calcium channel (VDCC), composed of four ( $\alpha 1, \alpha 2, \beta$, and $\delta)$ subunits. Four isoforms of beta subunits $(\beta 1, \beta 2, \beta 3, \beta 4)$ are known to exist. The cytoplasmic $\beta$ subunits regulate the channel activity by accelerating the kinetics of activation and inactivation through phosphorylation. Regulation of calcium channel activities are also provided by alternative splicing of the $\beta$ subunits. To elucidate the genomic organization of the VDCC $\beta 3$ subunit gene, two genomic clones were isolated from human genomic liabrary using the whole rat cDNA for $\beta 3$ subunit as a probe. The $\beta 3$ subunit gene in lamda phage DNA was analyzed by Southern hybridization and sequencing. A $19.1 \mathrm{~kb}$ clone (2BHG13) contained the whole $\beta 3$ cDNA sequence, consisting at least 14 exons. The deduced amino acid sequence from the exons shows $97 \%$ similarity with that of rat gene. Two alternatively spliced forms of $\beta 3$ subunit at $5^{\prime}$-end were found. The $\beta 3$ subunit had many possible phosphorylation sites. Alternative splicing of $\beta 3$ subunit mRNA at 5 -end and phosphorylation of the $\beta 3$ subunit protein may play a regulatory role in calcium influxes.
\end{abstract}

Keywords: voltage-dependent clacium channel, $\beta 3$ subunit, alternatively splicng, human genome, exon

\section{Introduction}

Since calcium ion was known as a necessary element in contraction of myocardial cells, several lines of experiment disclosed that calcium ion has an important physiological role and mediates many intracellular events; linking electrical activity to neurotransmitter release, excitationcontraction coupling in muscle, control of neuronal firing, and hormone release in endocrine cells (Hess, 1990). The concentration of calcium ion is finely tuned through a variety of calcium channels. Cytoplasmic calcium is raised by voltage-dependent calcium channel (VDCC) and $\mathrm{N}$-methyl-D-aspartate (NMDA) receptor through the plasma membrane, and 1,4,5-Inositol triphosphate (IP3) receptor or ryanodine receptor through the endoplasmic reticulum membrane. After its physiological action has been accomplished, the calcium level returns to the basal by $\mathrm{Na}^{+} / \mathrm{Ca}^{2+}$ exchanger and $\mathrm{Ca}^{2+}$ ATPase.

The calcium channels are classified into L-, N-, P- and T-type based on their electrophysiological and pharmacological properties. L-type calcium channel mediates the influx of calcium ion by strong depolarization under moderately depolarized condition and has binding sites for a member of calcium antagonists. N-type calcium channel exists in nervous system (Dubel et al., 1992) and P-type channel is abundant in Purkinje cells of cerebellum (Mori et al., 1991; Mintz et al., 1992). T-type channel can be opened transiently by small depolarization. Molecular properties of L-type calcium channel was well known because it is abundant at neuromuscular junction, and has specific drug binding sites (Tanabe et al., 1987). Biochemical studies show that skeletal dihydropyridinesensitive L-type VDCC is composed of five distinct subunits $(\alpha 1, \alpha 2, \beta, \gamma$, and $\delta)$ (Catterall, 1991 ; Singer et al., 1991 ; Kim et al., 1992). The $\alpha 1$ subunit is a transmembrane glycoprotein of $170 \mathrm{kD}$ which can be phosphorylated by protein kinase $A$. It has calcium pore and contains the binding sites for dihydropyridine, phenylalkylamine, and benzothiazepine. The $\alpha 2$ subunit is about $180 \mathrm{kD}$ in nonreducing condition, but can be divided to $\alpha 2$ subunit of $150 \mathrm{kD}$ and $\delta$ subunit of $25 \mathrm{kD}$ under reducing condition. The $\alpha 2$ and $\delta$ subunits come from a single transcript, that is processed into two pieces by posttrans-lational protease. The $\beta$ subunit, protein in cytosol, was shown to comprise of four ( $\beta 1, \beta 2, \beta 3$ and $\beta 4$ ) (Ruth et al., 1989; Pragnell et al., 1991; Hullin et al., 1992; Perez-Reyes et al., 1992; Castellano et al., 1993).

Although the $\alpha 1$ subunit is neccessary for the transport of calcium ions, it is not sufficient for the full activity. When the $\alpha 1$ subunit only was expressed in Xenopus oocyte, 
the channel activity was only $1 / 10$ of native one, and did not reveal the typical channel kinetics. Coinjection of skeletal muscle $\alpha 2-\delta$ and $\beta$ subunit mRNAs with the $\alpha 1$ subunit mRNA, however, drastically changed electrophysiological characteristics of the expressed calcium channels. Beta subunit is a cytoplasmic protein and accelerates the kinetics of activation (channel opening) and inactivation (channel closure) (Lacerda et al., 1991; Varadi et al.,1991). It regulates the channel activity by phosphorylation through PKA and protein kinase $\mathrm{C}$ that are activated by various signal transduction mechanisms. These findings suggest that $\beta$ subunits of the calcium channel may play a modulatory role in regulating calcium channel function (Ruth et al., 1989 ; Pragnell et al., 1991; Hullin et al., 1992).

According to recent data (Kim et al., unpublished observation), VDCC $\beta 3$ subunit gene is expressed only in the nervous system, and alternative splicing at 5 '-end was also observed. To elucidate the structure of the VDCC $\beta 3$ subunit gene the genomic DNA was isolated from human genomic liabrary and chracterized.

\section{Materials and Methods}

\section{Cloning of $\beta 3$ subunit gene of VDCC from human genomic library}

VDCC $\beta 3$ subunit gene was screened from human genomic DNA library (Stratagene 944201, W138 cell line from human lung fibroblast) using NG51 cDNA which has full coding region of VDCC $\beta 3$ subunit. About $7.0 \times 10^{5}$ plaques were screened with the cDNA probe which was labelled with $\left[\alpha-{ }^{32} P\right] d C T P$ using random-priming. The plaques were transfered onto nitrocellulose paper, immobilized, and hybridized with hybridization solution containing $[\alpha-$ ${ }^{32} \mathrm{P}$ ]dCTP labeled cDNA probe. The membrane was incubated in $6 \times$ SSC, $0.1 \%$ SDS, $5 \times$ Denhardt's reagent, $50 \%$ formamide, and $1 \times 10^{6} \mathrm{cpm} / \mathrm{ml}$ labeled probe at $42^{\circ} \mathrm{C}$ overnight. The membrane was washed with $0.2 \times$ SSC/ $0.1 \%$ SDS for $10 \mathrm{~min}$ three times at room temperature, followed by at $65^{\circ} \mathrm{C}$ for $10 \mathrm{~min}$ three times. After the autoradiography, the second screening was performed as above, and finally seven plaques were isolated.

The phage DNAs were purified and digested with Sacl, and Southern blot analysis was carried out. The hybridization condition was the same as described above. The probes used were a random-primed NG51 cDNA for confirming the clones and an end-labelled oligonucleotide corresponding to the 5'-end of NG51 for the selection of clones containing this sequence. The sequence of the oligonucleotide probe was 5'-TCC TCA AAC CCG GGC ACG TAG GAG TCG TCA TAC ATG-3'. The fragments positive for the probe were subcloned and their sequences were analyzed.

\section{Sequencing and data analysis}

The Sacl fragments of the genomic DNA were subcloned into pGEM $7 \mathrm{zf}(+)$ vector. The deletion mutants were prepared by Erase-a-base deletion kits according to the manufacturer's manual (Promega). To make deletion mutants the restriction maps were made. The $5^{\prime}-/ 3^{\prime}-$ overhang DNA were made and digested with ExollI nuclease followed by $S 1$ nuclease. The unidirectionally deleted DNA was ligated and transformation was carried out. Resulting plasmid DNAs from the deletion clones were prepared by Wizard miniprep kit (Promega). The sequencing template DNA was prepared by alkali denaturation of the double-stranded plasmid. The sequencing was carried out by the dideoxy-termination method using the Sequenase v. 2.0 (Amersham).

Cyclic sequencing was carried out using the SequiTherm cyclic sequencing kits (Epicentre Technologies). The oligonucleotide primer was end-labelled with $\left[\gamma^{32} \mathrm{P}\right]$ dATP using polynucleotide kinase. The sequencing reaction mixture is consisted of $50 \mathrm{ng}$ phage DNA, 1.5 pmol of ${ }^{32} \mathrm{P}$-labelled primer, 5 units of thermostable DNA polymerase, and dideoxynucleotides. The reaction mixtures were overlayed with mineral oil, and cycled 33 times as follows; $30 \mathrm{sec}$ at $95^{\circ} \mathrm{C}, 30 \mathrm{sec}$ at $50^{\circ} \mathrm{C}$, and 1 $\min$ at $70^{\circ} \mathrm{C}$. The reaction product was seperated on a $6 \%$ denaturing acrylamide gel and visualized by autoradiography.

The sequencing data from the deletion mutants and subclones were assembled by using the Assemblign program from IBI (New Haven, CT). Exon sequences were analyzed by comparing the genomic DNA sequences with cDNA sequence from NG51 cells. The exon sequence was translated into amino acid sequence, and possible phosphorylation and other motifs were searched using MacVector program (IBI).

\section{Results and Discussion}

Initially seven plaques were obtained by high stringency screening of the genomic library using NG51 cDNA. Out of seven clones only two clones, 2BHG13 and 2BHG14, were positive for Southern hybridization with NG51 cDNA probes. Their sizes were 19.1 and $18.0 \mathrm{~kb}$, respectively (Figure 1). 2BHG 13 had nine Sacl fragments, and 2BHG14 has five Sacl fragments.Two Sacl fragment from two clones were the same size, which suggested that the two genomic clones are overlapping. Another round of Southern blot analysis was carried out using the oligonucleotide probe corresponding to 5 '-end to identify whether $5^{\prime}$-end of the $\beta 3$ subunit gene is contained. 2BHG13 clones was positive for 5'-end of NG51, where first exon exists. 2BHG14 does not have the first exon, which could not be found in $2.85 \mathrm{~kb}$ upstream from the second exon. That is relevant to the negative result of 


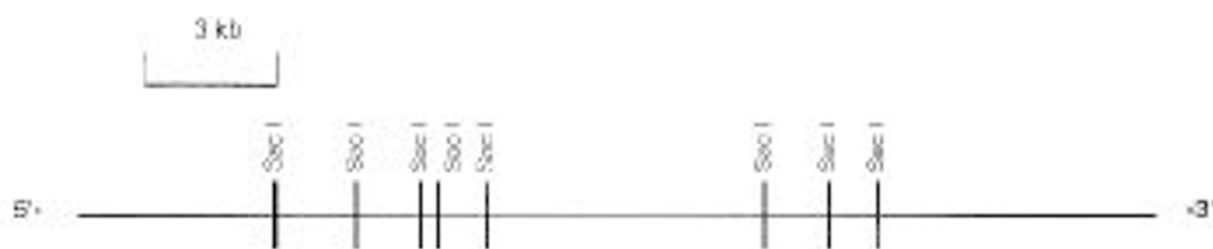

\section{BHG13} clone

2 BHG14

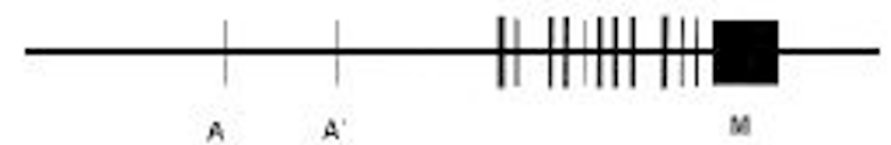

clone
Figure 1. The genomic structure of human $\beta 3$ subunit gene of VDCC. Two genomic clones were shown as thick lines and restriction sites were shown as thin lines. The BHG13 contains 14 exons from $A$ and $A^{\prime}$, and $M$ vertical bars indicates the exons. Each exons of $A$ and $A^{\prime}$ contain translation initiation codon and the exon $\mathrm{M}$ contains termination codon.

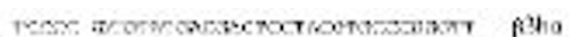

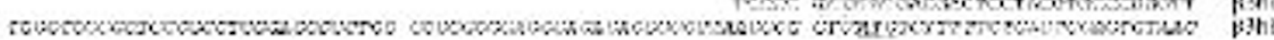

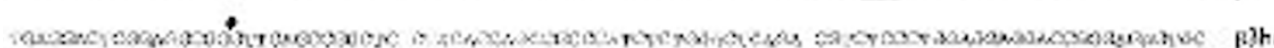

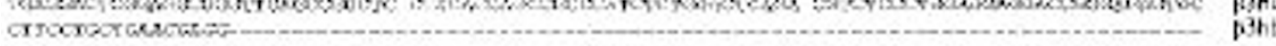
इ⿻一;

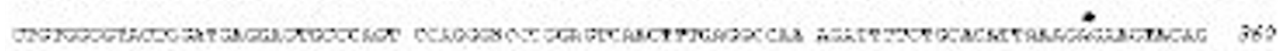

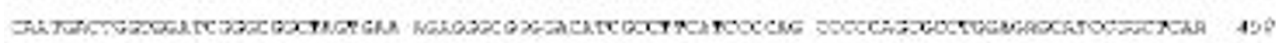
A3:

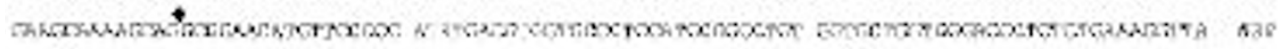

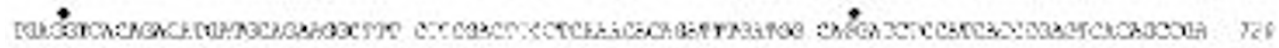

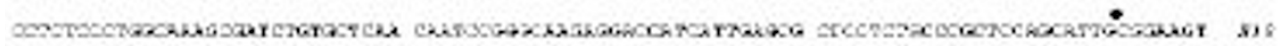

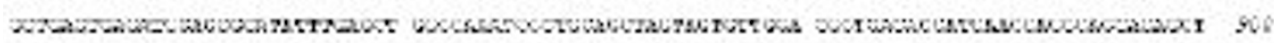

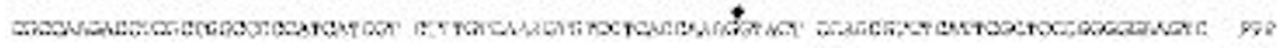

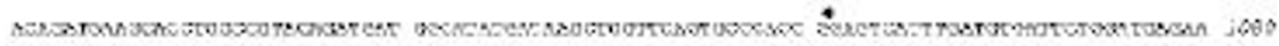

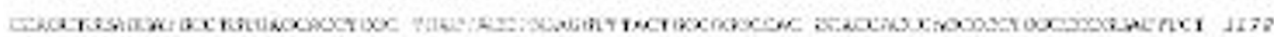

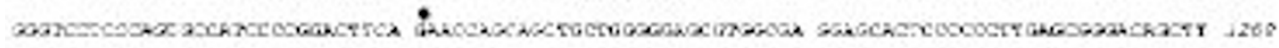

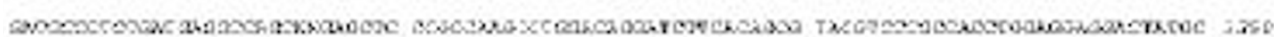

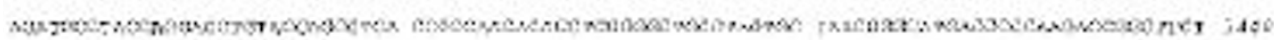

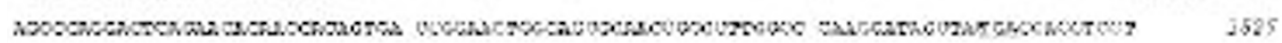

Figure 2. Nucleotide sequence of VDCC spliced from exons. Nucleotide sequence of VDCC $\beta 3$ subunit gene was obtained by splicing of the 14 exons from human genomic DNA. The nucleotide sequence shown as italic is the alternatively spliced variant of subunit gene. Splicing sites were marked with $(\bullet)$. The translation initiation codon at the first two exons and the termination codon at the 14 th exon were underlined.

Table 1. Exon/intron junction of 2BHG13 phage genomic clone.

\begin{tabular}{|c|c|c|c|c|c|c|}
\hline \multirow{2}{*}{$\begin{array}{l}\text { Exon } \\
\text { Name }\end{array}$} & \multirow{2}{*}{$\begin{array}{l}\text { Exon size } \\
\text { (bp) }\end{array}$} & \multicolumn{3}{|c|}{ Sequence at exon/intron junction } & \multirow{2}{*}{$\begin{array}{c}\text { Intron size } \\
(\mathrm{kb})\end{array}$} & \multirow{2}{*}{$\begin{array}{l}\text { Amino acid } \\
\text { interrupted }\end{array}$} \\
\hline & & 5 ' splice donor & & 3' splice acceptor & & \\
\hline$A$ & $>40$ & AAC GAG & gtgagcttcc & & 1.5 & \\
\hline$A^{\prime}$ & $>60$ & GAG GCG & gtgagtgccc------cccaacccag & GGT TCA GCA & 4.0 & Ala- 15 \\
\hline $\mathrm{B}$ & 123 & AGG GCC AAG & gtatactttc-----aattctccag & CAC AAA CCT & 0.2 & Lys- 56 \\
\hline C & 123 & ATT AAA GAG & gtgatcgacc------ctgcccccag & AAG TAC AGC & 0.5 & Glu- 97 \\
\hline $\mathrm{D}$ & 116 & AAG GCC AG & gtgagagttg-----ttcttctcag & G AGA TCT & 0.3 & Arg-136 \\
\hline $\mathrm{E}$ & 65 & TCT CTA G & gtagcctccc------ttccaaaaag & CC AAG CAG & 0.2 & Ala-158 \\
\hline $\mathrm{F}$ & 20 & CAA AAG CAG & gtgagtcaag------cattctgcag & GCG GAA CAT & 0.2 & Gln-164 \\
\hline $\mathrm{G}$ & 81 & GGT TAT CAG & gtgagaggat------cttcccccag & GTC ACA GAC & 0.2 & Glu-191 \\
\hline $\mathrm{H}$ & 59 & GAT GGC AG & gtaagctgcc------cccaccccag & G ATC TCC & 0.2 & Arg-211 \\
\hline I & 110 & AGC ATT G & gtgagaagtc------ccctccatag & CG GAA GTG & 0.6 & Ala-248 \\
\hline $\mathrm{J}$ & 152 & TCA CCA AAG & gtaagtcagc------ccccgctcag & GTA CTC CAG & 0.2 & Lys-298 \\
\hline $\mathrm{K}$ & 96 & TGC CCA CCG & gtgagtgcct------ccctccccag & GAG TCA TTT & 0.1 & Pro-330 \\
\hline $\mathrm{L}$ & 150 & GGA CTT CAG & gtgaaccatt------tggcccccag & AAC CAG CAG & 0.5 & Gln-380 \\
\hline M & $>835$ & exon/intron junc & ction not determined & & & \\
\hline
\end{tabular}




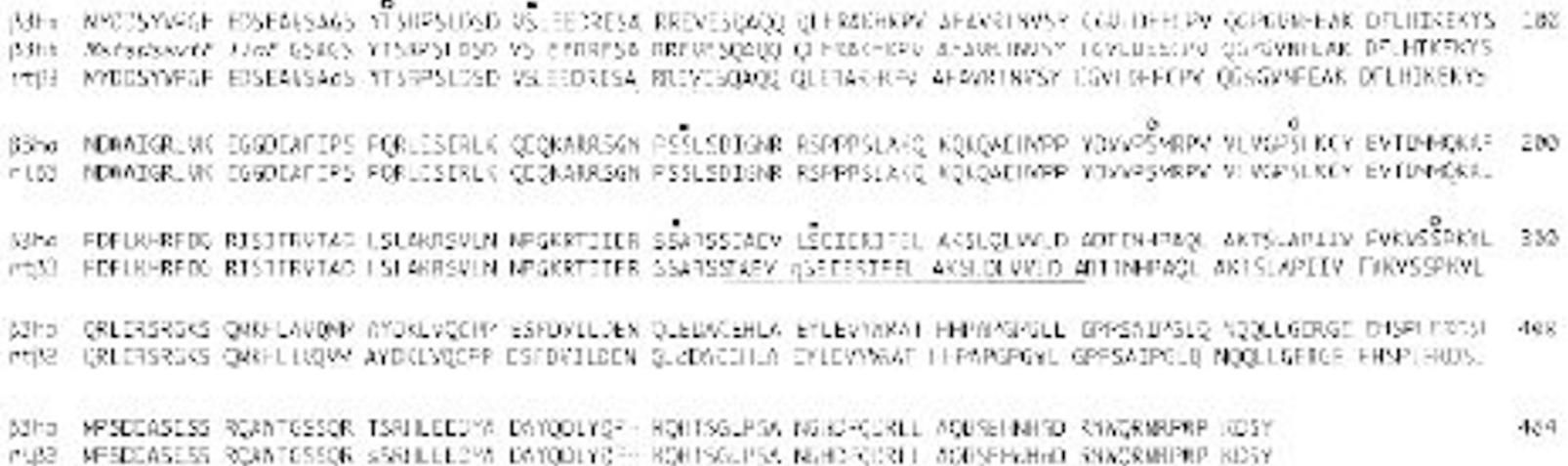

Southern analysis of 2BHG14 using the oligonucleotide probe. The analyzed result disclosed that the genomic clone, 2BHG13 encompasses the whole coding region of subunit gene, containing 14 exons from $A$ and $A^{\prime}$ to $M$ as shown on Figure1.

The first exon $A^{\prime}$, which has the nucleotide sequence of known $\beta 3$ subunit gene, was found in $0.7 \mathrm{~kb}$-size Sacl fragment. The $2 \mathrm{BHG} 13$ clone seemed to have another exon A located about $1.5 \mathrm{~kb}$ upstream of exon $\mathrm{A}^{\prime}$. The nucleotide sequence of exon $A$ was similar to that of alternatively spliced variant of rat $\beta 3$ subunit gene at $5^{\prime}-$ end (Kim et al.,unpublished observation). The second exon $\mathrm{B}$ was far from the first exon as shown in Table 1 and Figure 1. Most of the exons were clustered in 6.5and 1.3-kb Sacl fragments. $6.5 \mathrm{~kb}$ Sacl fragment has eight exons, and 1.3-kb Sacl fragment has four exons. The exon $M$ containing termination codon is located on 1.3-kb Sacl fragment. The exon-intron junction of $\beta 3$ subunit gene of VDCC is shown in Table 1. The size of intron in the BHG genome ranges from $118 \mathrm{bp}$ (between exon $\mathrm{K}$ and $\mathrm{L}$ ) to $597 \mathrm{bp}$ (between I and J). The size of the 14 exons varies from $21 \mathrm{bp}$ (exon $\mathrm{F}$ ) to more than $835 \mathrm{bp}$ (exon M). All introns begin with 'GT' and end with ' $A G$ '. The codon phases were variable, from the first to third base of codon.

The presumed nucleotide sequences spliced from the exons were shown at Figure 2 and the number of the nucleotide is 1525 . The open reversed triangle indicates the spliced junctions of the exons. Deduced amino acid sequence of $\beta 3$ subunit gene from the exons starts with methionine and was terminated at exon $\mathrm{M}$. The amino acid sequence has high degree of similarity with that of rat gene (Perez-Reyes et al., 1992) and identical to that of the human $\beta 3$ cDNA (Collin et al., 1994). Alternatively spliced forms of $\beta 1$, and $\beta 2$ subunits gene, which contribute to the functional diversity of the VDCC, were reported (Powers et al., 1992). Alternative splicing of $\alpha 1$ subunit and $\beta 1$ subunit confers the diversity of tissue specific regulation of calcium channel in various tissues. The genomic clones that we have cloned do not have the
Figure 3. Alignment of deduced amino acid sequences of human VDCC $\beta 3$ subunit gene with that of rat. The human $\beta 3$ sequences ( $\beta 3$ ha and $\beta 3 \mathrm{hb}$ ) are obtained by splicing of the exons and translation of the exon sequences. The nucleotide sequence shown in italic is the alternatively spliced variant of subunit gene. Identical sequences were shown as capital letter and nonidentical sequences were marked as lower cases. The conserved potential sites for phosphorylation are indicated with the following symbols: protein kinase $\mathrm{C}(\bigcirc)$, casein kinase II $(\boldsymbol{\square})$. Underline shows the predicted helices deduced from protein analysis program.

exons which could be alternatively spliced in the middle of the gene as $\beta 1$ subunit (Powers et al., 1992; Williams et al., 1992) but at 5'-end (Kim et al., unpublished observation). Although the marked differential expression of the spliced variant could not be obseved, the alternatively spiced form might have different kinetic properties and the diversity of $\beta 3$ subunit gene could confer the regulatory role of calcium channel activity.

The nucleotide sequences from the exons were translated into amino acid sequences (Figure 3). Deduced amino acid sequences of human $\beta 3$ subunit of VDCC was compared with that of rat, which showed the $98 \%$ similarity, but it is less similar to $\beta 1$ or $\beta 2$ subunit of VDCC as $75 \%$ and $78 \%$ respectively (data not shown). The computer analysis of the amino acid sequence of the $\beta 3$ subunit reveals that $\beta 3$ subunit does not have typical membrane-spanning region but contains three major $\alpha$ helical domains. The $\beta 3$ subunit of VDCC has many possible phosphorylation sites. Potential protein kinase $C$ (Ser/Thr-X-Lys/Arg) domains were found at 4 locations and 4 possible casein kinase II domains (Ser/Thr-X-XAsp/Glu) were observed. No consensus sequence for cAMP-dependent protein kinase was found in $\beta 3$ subunit gene.

Calcium currents through the cardiac and skeletal muscular VDCC are known to be modulated by phosphorylation mediated through several protein kinases, protein kinase C, cAMP-dependent protein kinase, etc (Ruth et al., 1989; Hullin et al., 1992; Castellano et al., 1993). Although it has been demonstrated that preferred substrate for protein kinases are the $\alpha 1$ subunits, $\beta$ subunits have several potential phosphorylation sites (Catterall, 1991; 
Hullin et al., 1992; Castellano et al., 1993). Among them possible phosphorylation sites for protein kinase $\mathrm{C}$ were the most abundant, but possible phosphorylation sites for cAMP-dependent kinase and cGMP-dependent kinase did not appear. These suggests that phosphorylation through the activation of the protein kinase $C$ system might be an important regulatory machinary in calcium signalling.

The $\beta 3$ subunit protein is supposed to have theoretical 3 major $\alpha$-helical domains. The $\beta 1$ subunit protein was known to have $4 \alpha$-helical domains, and the first two $\alpha$ helical domains was proposed to be a binding domain to the $\alpha 1$ subunit of skeletal muscle type VDCC (Waard et al., 1994). Missing the second $\alpha$-helical domain in the $\beta 3$ subunit might contribute to the different binding patterns with various $\alpha 1$ subunits. It is not characterized that which type of $\alpha 1$ subunits take part in the functional calcium channel with $\beta 3$ subunits. Our recent result on colocalization of $\beta 3$ and $\alpha 1 \mathrm{~B}$ by in situ hybridization suggests that the $\beta 3$ subunits is the partner subunit of $\alpha 1$ subunit of $P$-type calcium channel.

\section{Acknowledgement}

This study was supported by a grant (951-0709-035-2) from the Korea Science and Engineering Foundation, Korea, 1995, awarded to Hyung-Lae Kim.

\section{References}

Castellano, A., Wei X, Birnbaumer, L. and Perez-Reyes, E.(1993) Cloning and expression of a third calcium channel $\beta$ subunit. J. Biol. Chem. 268: 3450-3455

Catterall, W. A.(1991) Functional subunit structure of voltage-gated calcium channels. Science 253:1499-1553

Collin, T., Lory, P., Taviaux, S., Courtieu, C., Guilbault, P., Berta, P. and Nargeot, J. (1994) Cloning, chromosomal location and functional expression of the human voltagedependent calcium-channel beta 3 subunit. Eur. J. Biochem. 220: 257-262

Dubel, S. J., Starr, T. V. B, Hell, J., Ahlijanian, M. K., Enyeart, J. J., Catterall, W. A. and Snutch, T. P. (1992) Molecular cloning of the $\alpha 1$ subunit of an $\omega$-conotoxin-sensitive calcium channel. Proc. Natl. Acad. Sci. USA 89: 5058-5062

Hess, P. (1990) Cacium channels in vertebrate cells. Annu. Rev. Neurosci. 13: 337-356

Hullin, R., Singer-Lahat, D., Freichel, M., Beiel, M., Dascal, N., Hofmann, F. and Flockerzi, V. (1992) Calcium channel $\beta$ subunit heterogeneity: functional expression of cloned of CDNA from heart, aorta and brain. EMBO J. 11: 885-889

Kim, H.-L., Kim, H., Lee, P., King, R. G., and Chin, H. (1992) Rat brain expresses an alternatively spliced form of the dihydropyridine-sensitive L-type calcium channel $\alpha 2$ subunit. Proc. Natl. Acad. Sci. USA 89: 3251-3255

Lacerda, A. E., Kim, H. S., Ruth, P, Perez-Reyes, E., Flockerzi, V., Hofmann, F., Birnbaumer, L. and Brown, A. M.(1991) Normalization of current kinetics by interaction between the $\alpha 1$ and $\beta$ subunits of the skeletal muscle dihydropyridine-sensitive $\mathrm{Ca}^{2+}$ channel. Nature 352: 527-530

Mintz, I. M., Adams, M. E. and Bean, B. P.(1992) P-type calcium channel in rat central and peripheral neurons. Neuron $9: 85-95$

Mori, Y., Friedrich, T., Kim, M. S., Mikami, A., Nakai, J., Ruth, P., Bosse, E., Hofmann, F., Flockerzi, V., Furuichi, T., Mikoshiba, K., Imoto, K., Tanabe, T. and Numa, S.(1991) Primary structure and functional expression from complementary DNA of a brain calcium channel. Nature 350: 398-401

Perez-Reyes, E., Castellano, A., Kim, H. S., Bertrand, P., Baggstrom, E., Lacerda, A. E., Wei, X. and Birnbaumer, L.(1992) Cloning and expression of a cardiac/brain $\beta$ subunit of the L-type calcium channel. J. Biol. Chem. 267: 1792-1797

Powers, P. A., Liu, S., Hogan, K. and Gregg, R. G.(1992) Skeletal muscle and brain isoforms of a $\beta$-subunit of human voltage-dependent calcium channels are encoded by a single gene. J. Biol. Chem. 267: 22967-22972

Pragnell, M., Sakamoto, J., Jay, S. D. and Campbell, K. P.(1991) Cloning and tissuespecific expression of the brain calcium channel $\beta$-subunit. FEBS Lett. 291: 253-258

Ruth, P., Rohrkasten, A., Biel, M., Bosse, E., Regulla, S., Meyer, H. E., Flockerzi, V. and Hofmann, F.(1989) Primary structure of the $\beta$ subunit of the DHP-sensitive calcium channel from skeletal muscle. Science 245: 1115-1118

Singer, D., Biel, M., Lotan, I., Flockerzi, V., Hofmann, F. and Dascal, N. (1991) The roles of the subunits in the function of the calcium channel. Science 253: 1553-1556

Tanabe, T., Takeshida, H., Mikami, A., Flockerzi, V., Takahashi, H., Kangawa, K., Kojima, M., Matsuo, H., Hirose, T. and Numa, S. (1987) Primary structure of the receptor for calcium channel blockers from skeletal muscle. Nature 328: 313-318

Varadi, G,, Lory, P., Schultz, D., Varadi, M. and Schwartz, A. (1991) Acceleration of activation and inactivation by the $\beta$ subunit of the skelet $\alpha 1$ muscle calcium channel. Nature 352: 159-162

Waard, M. D., Pragnell, M. and Campbell, K. P. (1994) $\mathrm{Ca}^{2+}$ channel regulation by conserved $\beta$ subunit domain. Neuron 13: 495-503

Williams, M. E., Feldman, D. H., Mccue, A. F., Brenner, R., Velicelebi, G., Ellis, S. B. and Harpold, M. M. (1992) Structure and functional expression of $\alpha 1, \alpha 2$, and $\beta$ subunits of a novel human neuronal calciuim channel subtype. Neuron 8: 71-84 